\title{
Heme oxygenase-1 promotes neuron survival through down-regulation of neuronal NLRP1 expression after spinal cord injury
}

Wen-Ping Lin ${ }^{1+}$, Gong-Peng Xiong ${ }^{2+}$, Qing Lin ${ }^{3+}$, Xuan-Wei Chen ${ }^{4}$, Li-Qun Zhang ${ }^{4}$, Jin-Xing Shi ${ }^{1}$, Qing-Feng Ke ${ }^{1 *}$ and Jian-Hua Lin ${ }^{4^{*}}$

\begin{abstract}
Background: Understanding the mechanisms underlying neuronal death in spinal cord injury (SCI) and developing novel therapeutic approaches for $\mathrm{SCl}$-induced damage are critical for functional recovery. Here we investigated the role of heme oxygenase-1 (HO-1) in neuroprotection after SCl.

Methods: Adeno-associated virus expressing HO-1 was prepared and injected into rat spinal cords before SCl model was performed. HO-1 expression, inflammasome activation, and the presence of inflammatory cytokines were determined by quantitative polymerase chain reaction, immunohistological staining, immunoblot, and immunoprecipitation. Neuronal apoptosis was assessed by terminal deoxynucleotidyl transferase dUTP nick end labeling. The hindlimb locomotor function was evaluated for extent of neurologic damage. In an in vitro model, hydrogen peroxide was used to induce similar inflammasome activation in cultured primary spinal cord neurons, followed by evaluation of above parameters with or without transduction of HO-1-expressing adeno-associated virus.

Results: Endogenous HO-1 expression was found in spinal cord neurons after $\mathrm{SCl}$ in vivo, in association with the expression of Nod-like receptor protein 1 (NLRP1) and the formation of NLRP1 inflammasomes. Administration of HO-1-expressing adeno-associated virus effectively decreased expression of NLRP1, therefore alleviating NLRP1 inflammasome-induced neuronal death and improving functional recovery. In the in vitro model, exogenous HO-1 expression protected neurons from hydrogen peroxide-induced neuronal death by inhibiting NLRP1 expression. In addition, HO-1 inhibited expression of activating transcription factor 4 (ATF4), which is a transcription factor regulating NLRP1 expression.
\end{abstract}

Conclusions: $\mathrm{HO}-1$ protects spinal cord neurons after SCl through inhibiting NLRP1 inflammasome formation.

\section{Background}

Spinal cord injury (SCI) leads to complex cellular and molecular interactions within the central nervous system (CNS) in an attempt to repair the initial tissue damage. The pathophysiology of SCI is characterized by the shearing of cell membranes and axons, disruption of the blood-spinal cord barrier, cell death, immune cell

\footnotetext{
*Correspondence: qingfengke55@126.com; jianhua0918@126.com

${ }^{\dagger}$ Equal contributors

'Department of Orthopedic Surgery, the Second Affiliated Hospital, Fujian Medical University, Quanzhou 362000, China

${ }^{4}$ Department of Orthopedic Surgery, the First Affiliated Hospital, Fujian

Medical University, Fuzhou 350004, China

Full list of author information is available at the end of the article
}

transmigration, and myelin degradation [1]. There are two mechanisms of damage to the spinal cord after injury: the primary mechanical injury and the secondary injury mediated by multiple injury processes [2]. SCIinduced neuronal death in the lesion area seems to be the consequence of both the primary injury and the secondary injury depending on its localization and temporal process $[3,4]$. Several molecular biological processes, including changes of cell cycle-related gene expression, endoplasmic reticulum (ER) stress, glutamate excitotoxicity, free radical production, and inflammatory cytokine release contribute to neuronal death [1, 5-8]. Recently, 
inflammasome-associated neuronal programmed cell death, termed pyroptosis, has been shown to contribute to neuronal death in distinct neurological diseases [9-12]. Pyroptosis is induced by inflammasomes which consist of an apoptosis-associated speck-like protein containing a caspase recruitment domain (ASC), an adaptor protein, and caspase- 1 , an inflammatory cysteine-aspartic protease $[13,14]$. The formation of inflammasomes activates caspase- 1 and subsequently leads to plasma-membrane pore formation and cleavage of chromosomal DNA. Caspase-1 dependence is a defining feature of pyroptosis, and caspase- 1 is the enzyme that mediates this process of cell death [15]. In addition, caspase-1, also known as interleukin-1-converting enzyme, plays an important role in the inflammatory processes by cleaving pro-IL-1 $\beta$ into mature pro-inflammatory IL-1 $\beta$ [16]. IL-1 $\beta$ can be produced and released by CNS neurons following distinct stimulation and insults, suggesting that neurons are also a source of neuroinflammation [9, 17-20]. Inflammasome activation and formation have been shown to be present in the CNS cells including spinal cord neurons after CNS injury. For example, CNS trauma promotes the expression of the NOD-like receptor protein-1 (NLRP1), ASC, and caspase-1 in spinal cord motor neurons and cortical neurons [21]. NLRP1 inflammasome formation occurs in neurons after stroke in rodents [19]. NLRP1 inflammasomes are activated in patients with medial temporal lobe epilepsy and contribute to neuronal pyroptosis in the amygdala kindling-induced rat model [12]. Therefore, inhibition of inflammasome-mediated neuronal death could be neuroprotective in several neurological disorders.

Heme oxygenases (HO) are evolutionarily conserved enzymes that catabolize heme into equimolar amounts of labile Fe, carbon monoxide, and biliverdin [22]. HO have two types: HO-1 expression is induced ubiquitously in response to various stresses, whereas $\mathrm{HO}-2$ is constitutively expressed and can be further induced by opioids and glucocorticoids [23-27]. HO and its by-product carbon monoxide were found to blunt the stress axis activation secondary to many stimuli including immune-inflammatory stressors [28-30]. A previous study showed that both HO-1 messenger RNA (mRNA) and protein are elevated in the ventral horn motor neurons shortly after experimental SCI [31]. In addition, HO-1 modulates the secondary injury process, and high HO-1 expression may preserve spinal cord function in the early stages after SCI [32]. Moreover, HO-1 stabilizes the blood-spinal cord barrier and limits oxidative stress and white matter damage in acutely injured murine spinal cord [33]. Therefore, induction of HO-1 expression could be a therapeutic approach for SCI. However, the relationship between $\mathrm{HO}-1$ and inflammasome-mediated neuronal death has not been studied in SCI.

In this study, we examined the neuroprotective role of HO-1 in SCI and explored the feasibility of using HO-1- expressing adeno-associated virus (AAV) as a therapeutic approach for alleviating neuronal death in the acute phase of SCI. We found that NLRP1 inflammasomes were assembled and activated in neurons in the injury region after SCI. HO-1 expression was also induced in neurons at the same region shortly after SCI. In an in vitro model, we found that exogenous HO-1 expression protected neurons from NLRP1 inflammasomemediated neuronal death by inhibiting NLRP1 expression, conversely silencing endogenous HO-1 expression with small interfering RNA (siRNA) increased neuronal death. In addition, HO-1 inhibited expression of activating transcription factor 4 (ATF4), which is a transcription factor regulating NLRP1 expression. Moreover, administration of HO-1-expressing AAV into the spinal cord before SCI effectively decreased the expression of ATF4 and NLRP1 after SCI, therefore alleviating neuronal death and improving functional recovery. Taken together, our study indicated that HO-1 protects spinal cord neurons through inhibition of NLRP1 inflammasome formation.

\section{Methods \\ Animals and $\mathrm{SCl}$ model}

Adult male Sprague-Dawley rats $(280-320$ g) were used in this study. The animal experiments were performed in accordance with the guidelines of Laboratory Animals and were approved by the Animal Care and Use Committee of Fujian Medical University. Spinal cord compression at T12 was performed following an established static compression model [34]. Briefly, animals were anesthetized by inhalation of $2-3 \%$ isoflurane administered at a flow rate of $1 \mathrm{~L} / \mathrm{min}$. Midline skin incisions were performed to expose the T12 spinous processes. A laminectomy was performed at T12. The compression was applied by suspending the base of a compression platform (area $2 \times 5 \mathrm{~mm}^{2}$ ) onto the exposed cord. A weight of $50 \mathrm{~g}$ was applied statically to the platform for exactly $5 \mathrm{~min}$. After removing the platform, the muscles and skins were sutured. In the sham group, only a laminectomy was performed.

\section{Primary spinal cord neuron culture and $\mathrm{H}_{2} \mathrm{O}_{2}$ treatment}

Primary spinal cord neuron culture was conducted following the established method with minor modifications $[35,36]$. Briefly, spinal cords were dissected from E16 rat embryos. Isolated spinal cords free of meninges and dorsal root ganglia were digested with $0.25 \%$ Trypsin in Hank's balanced salt solution (HBSS, Hyclone) at $37{ }^{\circ} \mathrm{C}$ for $30 \mathrm{~min}$. The cell suspension was titrated in Dulbecco's Modified Eagle Medium (DMEM) supplemented with $1 \%$ penicillin-streptomycin and $10 \%$ fetal bovine serum (FBS, Hyclone). Then $8 \times 10^{5}$ cells, $4 \times 10^{5}$ cells, or $1 \times 10^{5}$ cells were seeded into each well of poly-Llysine-coated 6-well plates, 24-well plates, or 96-well 
plates, respectively. To treat primary neurons, $\mathrm{H}_{2} \mathrm{O}_{2}$ (Sigma-Aldrich) was added into the neuron culture at the final concentration of $10 \mu \mathrm{M}$.

\section{Preparation of adeno-associated virus}

To produce AAV expressing $\mathrm{HO}-1$ (termed A-HO-1 thereafter), HO-1 complementary DNA (cDNA) was amplified by PCR and inserted to BamHI sites of pAAVCMV-EGFP and confirmed by sequencing. The recombinant plasmid was then packaged into AAV2/8 particles (AAV2 ITRs; AAV8 capsid). All these procedures were conducted by Neuronbiotech Company. The A-HO-1 titer was $5.5 \times 10^{12}$ genome copies $/ \mathrm{ml}$, and the titer of EGFP-expression control AAV2/8 virus (termed A-C hereafter) was $7.5 \times 10^{12}$ genome copies $/ \mathrm{ml}$. Viral titer was determined with quantitative PCR by the detection of WPRE element copies of AAV genome.

\section{AAV administration in vitro and in vivo}

To transduce primary neurons, on day 7 in vitro, $2.0 \times$ $10^{11}$ genome copies of AAV in $50 \mu \mathrm{l}$ of PBS were added into each well of six-well plates containing $1.5 \times 10^{5}$ cells in $1.5 \mathrm{ml}$ medium and were incubated for $24 \mathrm{~h}$ before further processing or treatment.

To assess the effect of A-HO-1 in vivo, the rats were randomly assigned to three groups including vehicle, A$\mathrm{C}$ and the A-HO-1 groups. Seven days before SCI, $3 \mu \mathrm{l}$ of normal saline was injected into the spinal cord of the vehicle group rats at $\mathrm{T} 12$ at a rate of $0.2 \mu \mathrm{l} / \mathrm{min}$ using a 5 - $\mu$ l micro-syringe with a 33-gauge needle (Hamilton). At the same time point using the same method, $3 \mu \mathrm{l}$ of A-C or A-HO-1 was injected into the rats of A-C group or A-HO-1 group, respectively. After injection, the injectors were removed and the muscles and skins were sutured in separate layers.

\section{siRNA transfection}

siRNAs for HO-1, NLRP1, and ATF4 were purchased from Santa Cruz Biotechnolgy. siRNAs (50 pmol each) were transfected into $1.5 \times 10^{5}$ primary neurons using RNAiMAX reagent (Life Technologies) according to manufacturer's protocol. After $24 \mathrm{~h}$, cells were subject to further processing including immunoblot and $\mathrm{H}_{2} \mathrm{O}_{2}$ treatment.

\section{Immunofluorescent staining}

The spinal cord was fixed with $4 \%$ paraformaldehyde and then was embedded in paraffin using a Leica APS300. Five-micron cross sections were prepared, and antigen retrieval was performed by boiling sections in sodium citrate buffer ( $10 \mathrm{mM}$ sodium citrate, $0.05 \%$ Tween 20, pH 6.0) for $30 \mathrm{~min}$. Anti-NLRP1 (Abcam), anti-HO-1 (Santa Cruz Biotechnology), and anti-MAP2 (Millipore) antibody were used for staining according to the manufacturer's instructions. Alexa Fluor 488 donkey anti-rabbit IgG and Alexa Fluor 594 chicken anti-goat IgG (both from Invitrogen) were used as secondary antibodies. The sections were observed on a Leica DMIRE2 inverted fluorescent microscope.

\section{Terminal deoxynucleotidyl transferase dUTP nick end labeling (TUNEL)}

Primary neuron culture or spinal cord sections were labeled with DeadEnd ${ }^{\text {Tx }}$ Fluorometric TUNEL System (Promega) following the manufacturer's manual. The sections were observed on a Leica DMIRE2 inverted fluorescent microscope.

\section{RNA isolation, reverse transcription, and quantitative RT-PCR (q-RTPCR)}

Total RNA was extracted from cells or tissues using the RNeasy Mini Kit (Qiagen). cDNA synthesis was performed using SuperScript III First-Strand Synthesis System (Invitrogen). q-RTPCR was performed using Fast SYBR Green Master Mix (Invitrogen) on a 7300 q-RTPCR System (Invitrogen). Data was analyzed with 7300 system software (Invitrogen). Primer sequences for each gene are as follows: $\beta$-actin (5 -ACAACCTTCTTGCAGCTCCTC-3 and 5 -C TGACCCATACCCACCATCAC-3 ). TNF- $\alpha$ (5 -TCGGTC CCAACAAGGAGGAG-3) and (5 -GGGCTTGTCACTC GAGTTTTG-3 ). IL-1 $\beta$ (5 -TGTCTGACCCATGTGAGC TG-3 ) and (5 -GCCACAGGGATTTTGTCGTT-3 ). NLR P1 (5 -GTGGCTGGACCTCTGTTTGA-3) and (5 -GGC GTTTCTAGGACCATCCC-3 ). NLRP3 (5 -CCAGAGCC TCACTGAACTGG-3) and (5 -AGCATTGATGGGTCA GTCCG-3 ). NLRC4 (5 -AGGCAAACTGGATTTGCTT GG-3) and (5 -TGTGGTGAGTCAAACCGTCC-3 ). ASC (5 -GGACAGTACCAGGCAGTTCG-3) and (5 -GTCAC CAAGTAGGGCTGTGT3). Caspase-1 (5 -GACCGAGT GGTTCCCTCAAG-3) and (5 -GACGTGTACGAGTG GGTGTT-3 ). ATF4 (5 -ACCATGGCGTATTAGAGG CA-3) and (5 -GCTGGTATCGAGGAATGTGC-3 ). PCR conditions used for all primer sets were as follows: $95{ }^{\circ} \mathrm{C}$ hot start for $10 \mathrm{~min}$, followed by 40 amplification cycles of $95{ }^{\circ} \mathrm{C}$ for $15 \mathrm{~s}$ (denaturing), $60{ }^{\circ} \mathrm{C}$ for $1 \mathrm{~min}$ (annealing, extension, and detection). Relative abundance of RNA was analyzed using $2^{-\Delta \Delta \mathrm{Ct}}$ method.

\section{Immunoblot assay}

The following antibodies were used for immunoblot: anti- $\beta$-actin, anti-ASC, anti-HO- 1 , anti-HO-2, antiATF4, and anti-CHOP antibodies were purchased from Cell Signaling Technology. Anti-NLRP1, anti-NLRP3, anti-NLRC4, anti-AIM2, and anti-pro-caspase-1 antibodies were purchased from Abcam. Anti-caspase-1 antibody (against both pro-caspase-1 and p20) was purchased from Santa Cruz Biotechnology. Anti-IL-1 $\beta$ 
(against both pro-IL-1 $\beta$ and mature IL-1 $\beta$ ) was purchased from Novus Biologicals.

\section{Co-immunoprecipitation}

To assess the formation of NLRP1 inflammasome, spinal cord tissues or cultured neurons were lysed in $50 \mathrm{mM}$ Tris- $\mathrm{HCl}(\mathrm{pH} 7.4), 150 \mathrm{mM} \mathrm{NaCl}, 0.5 \% \mathrm{NP}-40$, and complete protease inhibitors (Roche). Five hundred micrograms of spinal cord lysates from sham or SCI animals, or primary neuron homogenates, were incubated on ice for $15 \mathrm{~min}$ and then centrifuged at $2600 \times \mathrm{g}$ for $5 \mathrm{~min}$ at $4{ }^{\circ} \mathrm{C}$ to remove tissue/cell debris. Immunoprecipitation assays were performed using $1 \mathrm{mg}$ magnetic Dynabeads (Invitrogen) coupled to $7 \mathrm{mg}$ of anti-NLRP1 (Abcam) or anti-ASC (Cell Signaling Technology) antibody according to the manufacturer's instructions. Briefly, $250 \mu \mathrm{g}$ of lysate applied to $1.5 \mathrm{mg}$ of anti-NLRP1 or anti-ASC antibody-coupled magnetic beads, incubated overnight at $4{ }^{\circ} \mathrm{C}$ on a rotator, and eluted in a low $\mathrm{pH}$ buffer. Pre-immune serum (Abnova) served as a negative control. Elutions were collected and added to $\times 1$ Laemmli buffer to dissociate proteins. Five microliters of $1 \mathrm{M}$ Tris $(\mathrm{pH}$ 9.8) were added to match the $\mathrm{pH}$ of the stacking gel. Samples were then boiled for 5 min and subjected to SDS-PAGE and immunoblot analysis with indicated antibodies.

\section{Neurologic evaluation}

The hindlimb locomotor function was assessed at preinjury and $1,3,7,14$, and 21 days after SCI using the BBB locomotor test developed by Basso et al. [37]. The hindlimb movements during locomotion were quantified using a scale ranging from 0 to 21 . The rats were observed for $5 \mathrm{~min}$ at each time point by two observers who were blinded to the experimental protocol.

\section{Statistics}

Data was presented as mean \pm SD and analyzed by statistical software (Prism 6.0, GraphPad Software). Student's $t$ test or one-way ANOVA was used for comparison of mean between the groups. For BBB score analysis, repeated-measures ANOVA was used. $p$ values $<0.05$ were considered significant.

\section{Results}

\section{$\mathrm{SCl}$ induces expression of inflammasome components}

The activation of inflammasome pathways in neurological disorders including SCI has been documented previously [38]. To investigate the temporal dynamics and types of inflammasomes after SCI, we firstly determined mRNA levels of different inflammasome components in the injury region at different time points after SCI. We found that NLRP1 mRNA was significantly elevated from 18 to $24 \mathrm{~h}$ after SCI. NLRP3 mRNA was slightly up-regulated at $6 \mathrm{~h}$ but returned to basal level at $18 \mathrm{~h}$. There was not significant change of NLRC4 mRNA level. Caspase-1 mRNA and ASC mRNA were also upregulated after SCI (Fig. 1a). Immunoblot showed consistent increases in the protein levels of NLRP1, caspase-1, and ASC (Fig. 1b, c). However, protein levels of NLRP3 and NLRC4 were not significantly altered (Fig. 1b). The increase of NLRP1 expression was confirmed by histological staining, and it seemed that neurons express NLRP1 (Fig. 1d). The expression of pro-inflammatory cytokines IL-1 $\beta$ and TNF- $\alpha$ was also increased at $6 \mathrm{~h}$ after $\mathrm{SCI}$ and remained at high levels until $24 \mathrm{~h}$ (Fig. 1e).

\section{$\mathrm{SCl}$ induces NLRP1 inflammasome activation}

To determine whether NLRP1 inflammasomes are formed after SCI, the processing of pro-caspase-1 and pro-IL-1 $\beta$ was tested. SCI induced significant increases in both pro-caspase- 1 and caspase- 1 p20 levels, suggesting that pro-caspase- 1 was substantially cleaved to become activated caspase- 1 by inflammasome formation (Fig. 2a). Consistently, mature IL-1 $\beta$ level was also upregulated after $\mathrm{SCI}$, suggesting that activated caspase-1 cleaved pro-IL-1 $\beta$ into mature IL-1 $\beta$ (Fig. 2b). To characterize the association of inflammasome proteins after SCI, co-immunoprecipitations of post-SCI spinal cord lysates were performed using anti-ASC antibody, anti-NLRP1 antibody, and pre-immune serum, respectively. As shown in Fig. 2c, in the sham spinal cord, ASC was immunoprecipitated with anti-ASC antibody, and low levels of NLRP1 and caspase-1 were present in this signaling complex. At $24 \mathrm{~h}$ after SCI, there was increased association of NLRP1 and caspase-1with ASC. In addition, the pro-caspase- 1 associated to ASC was cleaved to generate activated caspase-1, demonstrated by increased immunoprecipitated caspase-1 p20. Consistently, immunoprecipitation with anti-NLRP1 antibody showed increased association of ASC and pro-caspase-1 with NLRP1, in comparison with the sham control. As a negative control, pre-immune serum did not immunoprecipitate the inflammasome-associated proteins, indicating the antibody specificity. Taken together, our data suggested that SCI not only induced expression of NLRP1 inflammasome components but also triggered the assembly of inflammasomes.

\section{$\mathrm{SCl}$ induces HO-1 expression in spinal cord neurons}

HO-1 has been shown to be induced after SCI [31]. To confirm this, we examined expression of $\mathrm{HO}-1$ in the $\mathrm{SCI}$ region. As shown in Fig. 3a, b, HO-1 protein level was relatively low immediately after $\mathrm{SCI}$ and was not changed at $6 \mathrm{~h}$ after SCI. However, at $18 \mathrm{~h}$ after SCI, its expression was remarkably up-regulated and stayed high until $24 \mathrm{~h}$. Immunofluorescent staining revealed enhanced HO-1 expression in MAP2 ${ }^{+}$neurons, suggesting 

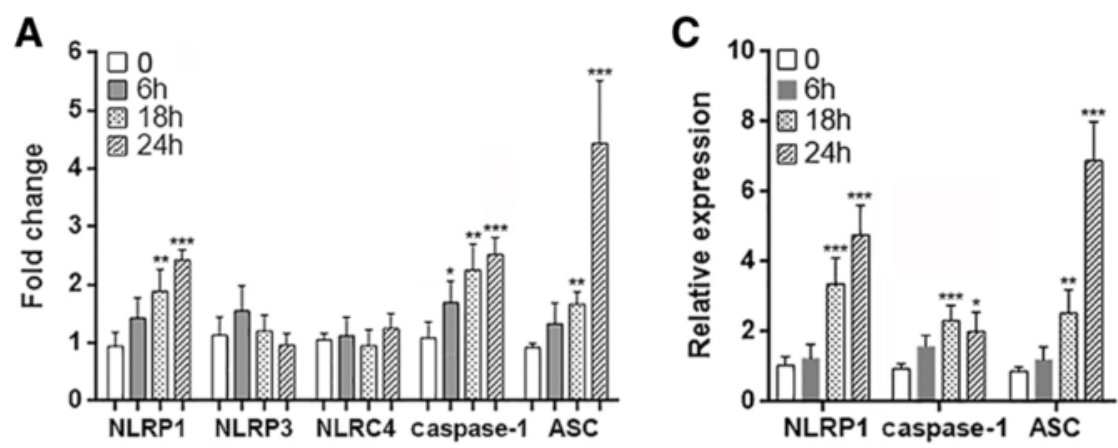

B
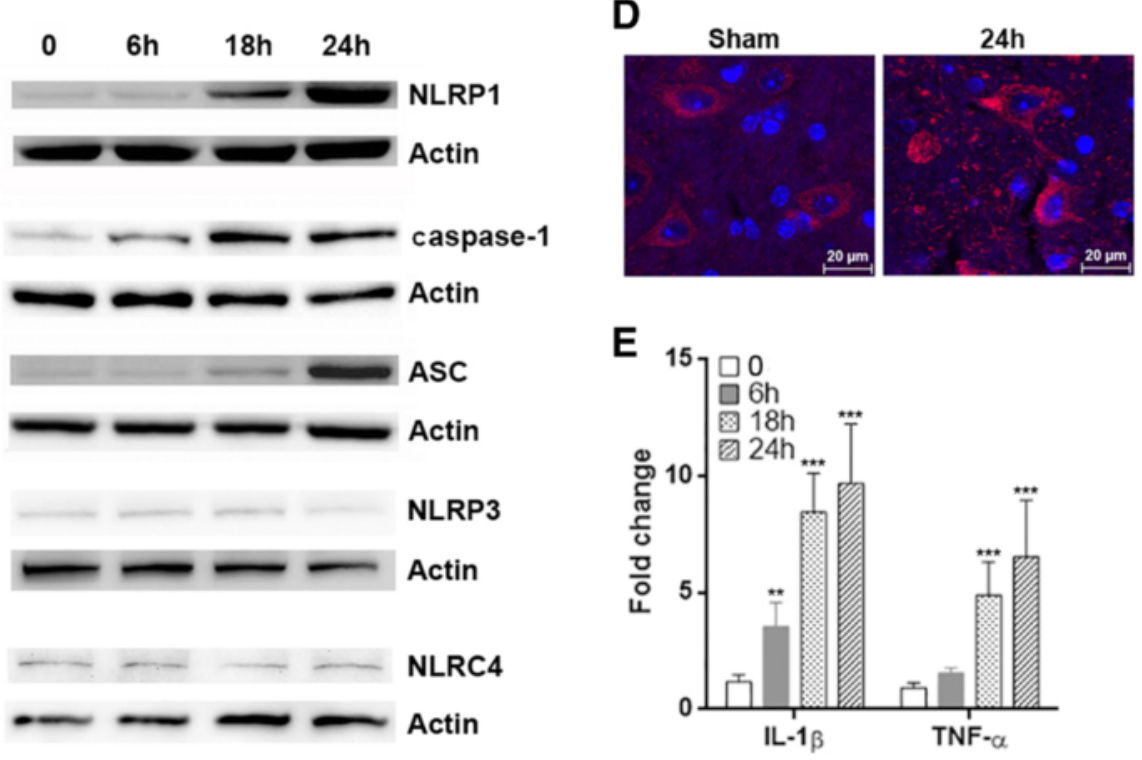

Fig. $1 \mathrm{SCl}$ induces expression of inflammasome components in the spinal cord. a mRNA levels of inflammasome components in injured spinal cords were determined by q-RTPCR at different time points after SCl. b Protein levels of inflammasome components in injured spinal cords were determined by immunoblot at different time points after SCl. c Statistical analysis for protein levels of inflammasome components in injured spinal cords after SCl. $\mathbf{d}$ Immunofluorescent staining of NLRP1 in spinal cords. e mRNA levels of IL-1 $\beta$ and TNF-a in the injured spinal cords were determined by q-RTPCR at different time points after SCl. 0: immediately after $\mathrm{SCl}$. $N=6$ per group. ${ }^{*} p<0.05$; ${ }^{* *} p<0.01$; ${ }^{* * *} p<0.001$ in comparison with the "0" group

that SCI induced HO-1 expression in spinal cord neurons (Fig. 3c).

\section{HO-1 inhibits NLRP1 expression to alleviate neuronal death induced by hydrogen peroxide}

To investigate the effect of $\mathrm{HO}-1$ on neuronal survival, we employed an in vitro model using $\mathrm{H}_{2} \mathrm{O}_{2}$ to induce neuronal damage. Primary spinal neurons were treated with $\mathrm{H}_{2} \mathrm{O}_{2}$ for $6 \mathrm{~h}$, and inflammasome signaling was evaluated. Similar to $\mathrm{SCI}, \mathrm{H}_{2} \mathrm{O}_{2}$ induced a significant increase in NLRP1 expression compared with untreated control, while expression of AIM2, NLRP3, and NLRC4 was not changed (Fig. 4a). Co-immunoprecipitation indicated that the association of ASC and pro-caspase-1 with NLRP1 was weak in untreated neurons, whereas $\mathrm{H}_{2} \mathrm{O}_{2}$ promoted the association of NLRP1 with ASC and pro-caspase-1, suggesting enhanced formation of NLRP1 inflammasomes (Fig. 4b). Of note, in $\mathrm{H}_{2} \mathrm{O}_{2}$-treated neurons, NLRP1-associated caspase-1 p20 was also higher than that in untreated neurons, suggesting caspase- 1 activation in $\mathrm{H}_{2} \mathrm{O}_{2}$-treated neurons (Fig. 4b). Therefore, $\mathrm{H}_{2} \mathrm{O}_{2}$ triggered a pattern of inflammasome activation similar to $\mathrm{SCI}$ and presented a viable in vitro model to simulate SCI-induced inflammasome activation. We then manipulated the expression of $\mathrm{HO}-1$ in this model by transfection of HO-1 siRNA or transduction of HO-1-expressing AAV (A-HO-1) into primary spinal neurons. In our preliminary study, HO-1 siRNA inhibited $\mathrm{HO}-1$ expression while not altering $\mathrm{HO}-2$ (Additional file 1: Figure S1A). Transduction of control AAV (A-C) did not significantly change the expression of HO-1 and NLRP1 (Additional file 1: Figure S1B), suggesting that AAV transduction procedure cannot alter HO-1 and NLRP1 expression. In addition, neither transfection of scramble siRNA nor transduction of control AAV triggered caspase-1 activation, suggesting 


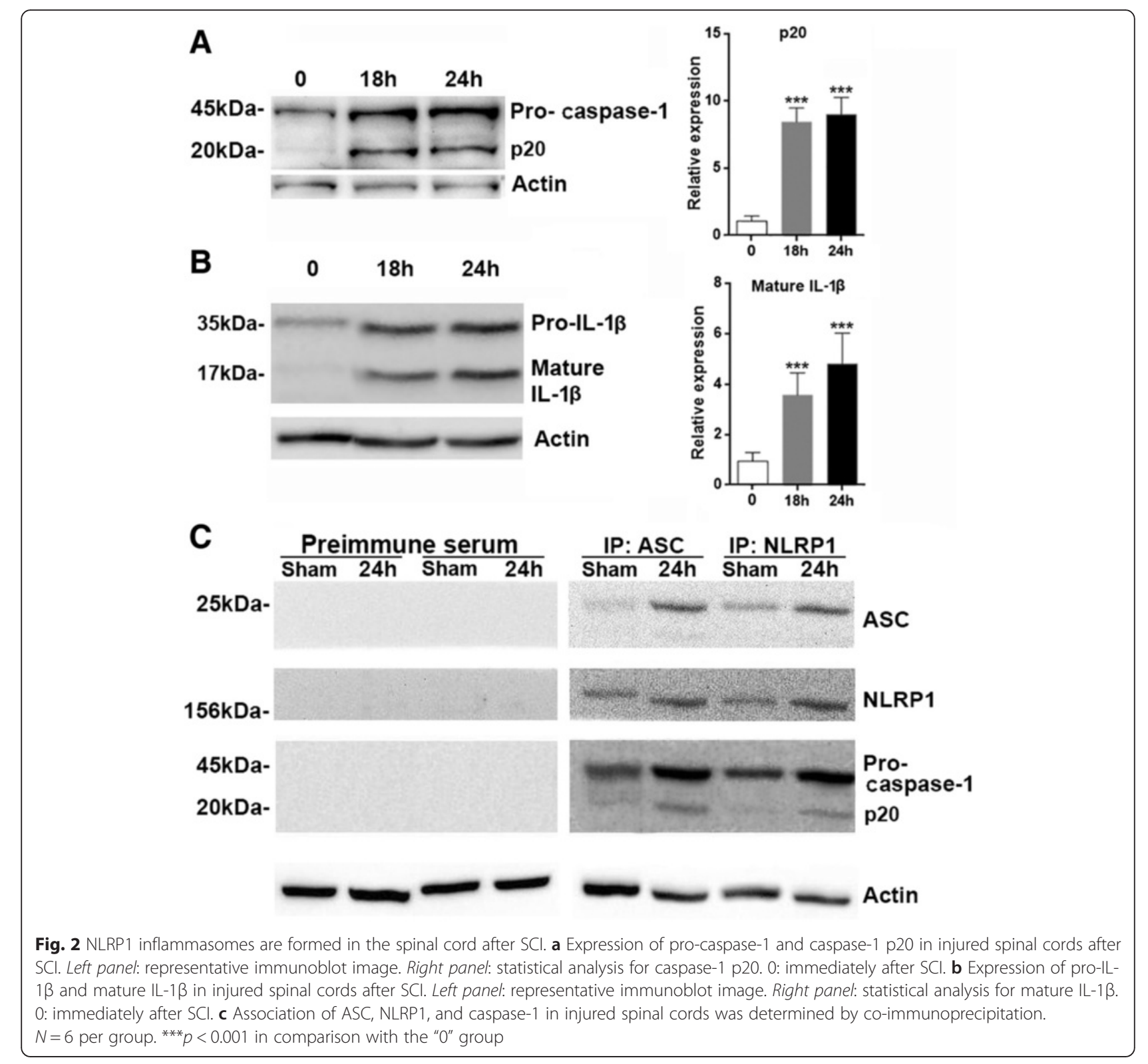

that inflammasome formation was not induced by the transfection or transduction procedures themselves (Additional file 1: Figure $\mathrm{S} 1 \mathrm{C}$ ). After $\mathrm{H}_{2} \mathrm{O}_{2}$ treatment, compared with vehicle control, A-HO-1 significantly increased HO-1 expression while down-regulating NLRP1 expression (Fig. 4c, d). Conversely, HO-1 siRNA reduced $\mathrm{HO}-1$ expression while up-regulating NLRP1 level (Fig. 4c, d). This data suggested that HO-1 negatively regulated NLRP1 expression in $\mathrm{H}_{2} \mathrm{O}_{2}$-treated neurons. Consistent with the change of NLRP1 expression, A-HO-1 significantly reduced caspase-1 activation, demonstrated by lower level of caspase-1 p20 when compared to vehicle control (Fig. 4e). HO-1 siRNA remarkably increased caspase-1 p20 level (Fig. 4e), suggesting that $\mathrm{HO}-1$ inhibited NLRP1 expression and subsequently decreased NLRP1 inflammasome-induced caspase-1 activation.

To investigate whether NLRP1 expression was related to neuronal death, we transfected primary neurons with NLRP1 siRNA before $\mathrm{H}_{2} \mathrm{O}_{2}$ treatment. NLRP1 siRNA effectively decreased NLRP1 expression and did not influence the expression of NLRP3 and NLRC4 (Additional file 1: Figure S1D and S1E). Neuronal death was evaluated by TUNEL at $12 \mathrm{~h}$ after $\mathrm{H}_{2} \mathrm{O}_{2}$ treatment. We found that $\mathrm{H}_{2} \mathrm{O}_{2}$ induced substantial TUNEL-positive cells, while A-HO-1 decreased TUNEL-positive cells, and HO-1 siRNA robustly increased TUNEL-positive cells (Fig. 4f, g). NLRP1 siRNA also significantly reduced TUNEL-positive cells after $\mathrm{H}_{2} \mathrm{O}_{2}$ treatment (Fig. 4f, g). Scramble siRNA transfection and control AAV 


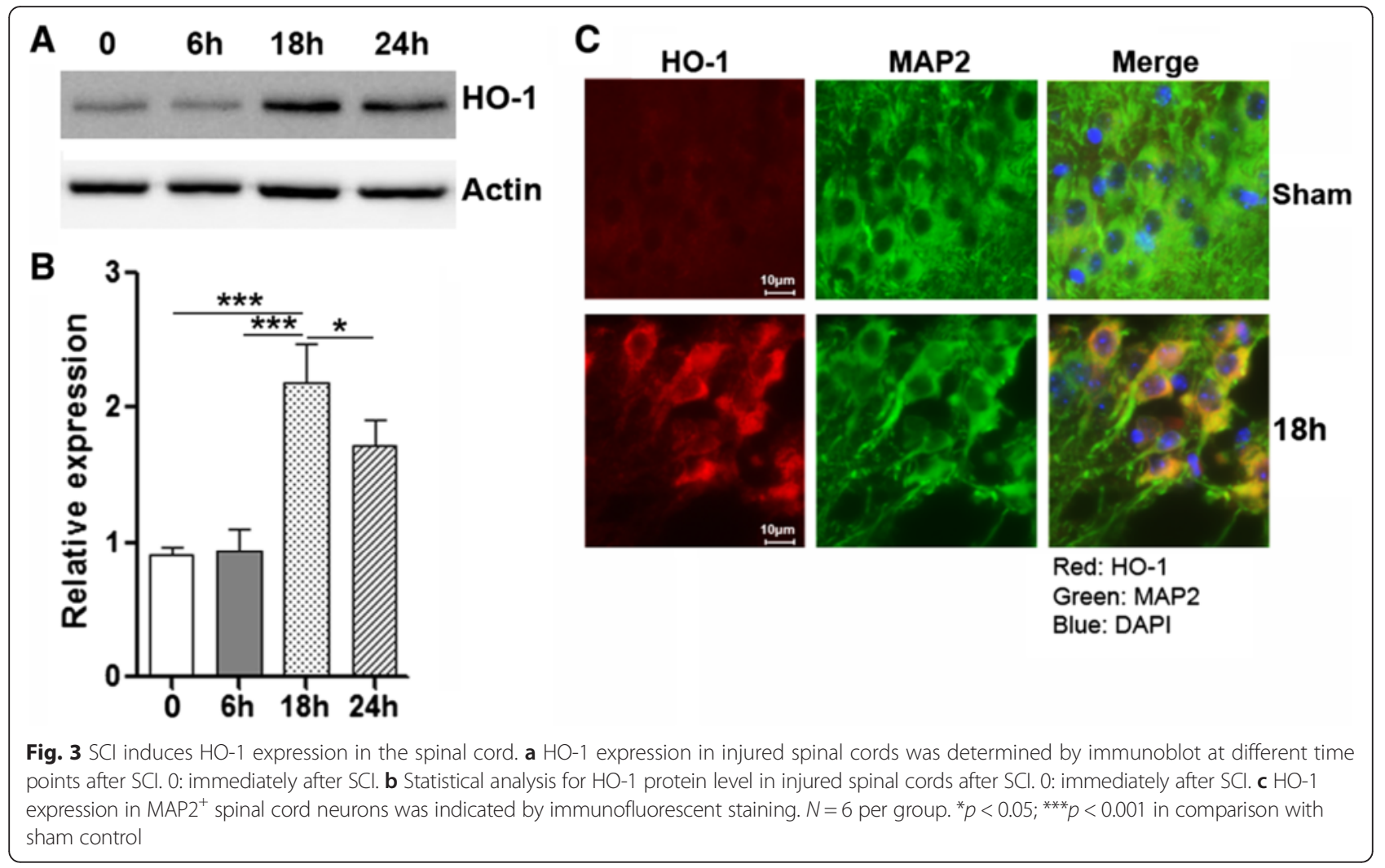

transduction did not significantly altered TUNEL staining (Additional file 1: Figure S2). Thus, our data indicated that NLRP1 induced neuronal death and HO-1 inhibited neuronal death through inhibiting NLRP1 expression.

\section{HO-1 regulates NLRP1 expression through ATF4}

A recent study indicates that transcription factor ATF4 induces NLRP1 expression during ER stress [39]. In addition, ER stress contributes to cell death and survival in a SCI model [40]. Therefore, we tested whether HO-1 could regulate NLRP1 expression via ATF4. We firstly checked the expression of ATF4 and its target C/EBP homology protein (CHOP) in $\mathrm{H}_{2} \mathrm{O}_{2}$-treated primary spinal cord neurons. $\mathrm{H}_{2} \mathrm{O}_{2}$ significantly up-regulated ATF4 and CHOP levels (Fig. 5a). To evaluate the role of ATF4 in regulating NLRP1 expression, we transfected primary spinal cord neurons with different concentrations of ATF4 siRNA before $\mathrm{H}_{2} \mathrm{O}_{2}$ treatment. As shown in Fig. 5b, the ATF4 mRNA level was decreased by ATF4 siRNA in a dose-dependent manner. Of note, the NLRP1 mRNA level was also decreased in association with the decrease of ATF4 mRNA, suggesting that ATF4 positively regulated NLRP1 expression. To investigate the role of ATF4 in $\mathrm{H}_{2} \mathrm{O}_{2}$-induced neuronal death, TUNEL was performed. We found that ATF4 siRNA inhibited neuronal death in a dose-dependent manner
(Fig. 5c). We then evaluated the effect of exogenous HO- 1 on ATF4 expression by transducing neurons with A-HO-1. When compared to non-transduced control cells, A-HO-1 significantly reduced ATF4 protein level (Fig. 5d) and mRNA level (Fig. 5e). To exclude the possibility that AAV transduction itself influences ATF4 expression, A-C was transduced into both untreated and $\mathrm{H}_{2} \mathrm{O}_{2}$-treated neurons. We found insignificant changes in ATF4 mRNA level between transduced and nontransduced neurons, suggesting AAV itself did not alter ATF4 expression (Additional file 1: Figure S3). Therefore, the change in A-HO-1-transfected neurons should be ascribed to the effect of $\mathrm{HO}-1$.

\section{HO-1 protects neurons from $\mathrm{SCl}$ in vivo}

Similar to in vitro $\mathrm{H}_{2} \mathrm{O}_{2}$ treatment, SCI induced upregulation of ATF4 and $\mathrm{CHOP}$ in the injury region of spinal cord (Fig. 6a). To evaluate whether HO-1 is neuroprotective after $\mathrm{SCI}$, we injected $\mathrm{A}-\mathrm{C}$ or $\mathrm{A}-\mathrm{HO}-1$ into the spinal cord 7 days before SCI. Injected A-C induced expression of EGFP (Additional file 1: Figure S4A) but did not influence the expression of ATF4, NLRP1, NLRP3, and NLRC4 in the spinal cord (Additional file 1: Figure S4B), suggesting that AAV injection successfully introduced exogenous genes into the spinal cord while not altering endogenous inflammasome-related gene expression. A-C also did not significantly alter $\mathrm{HO}-1$ 


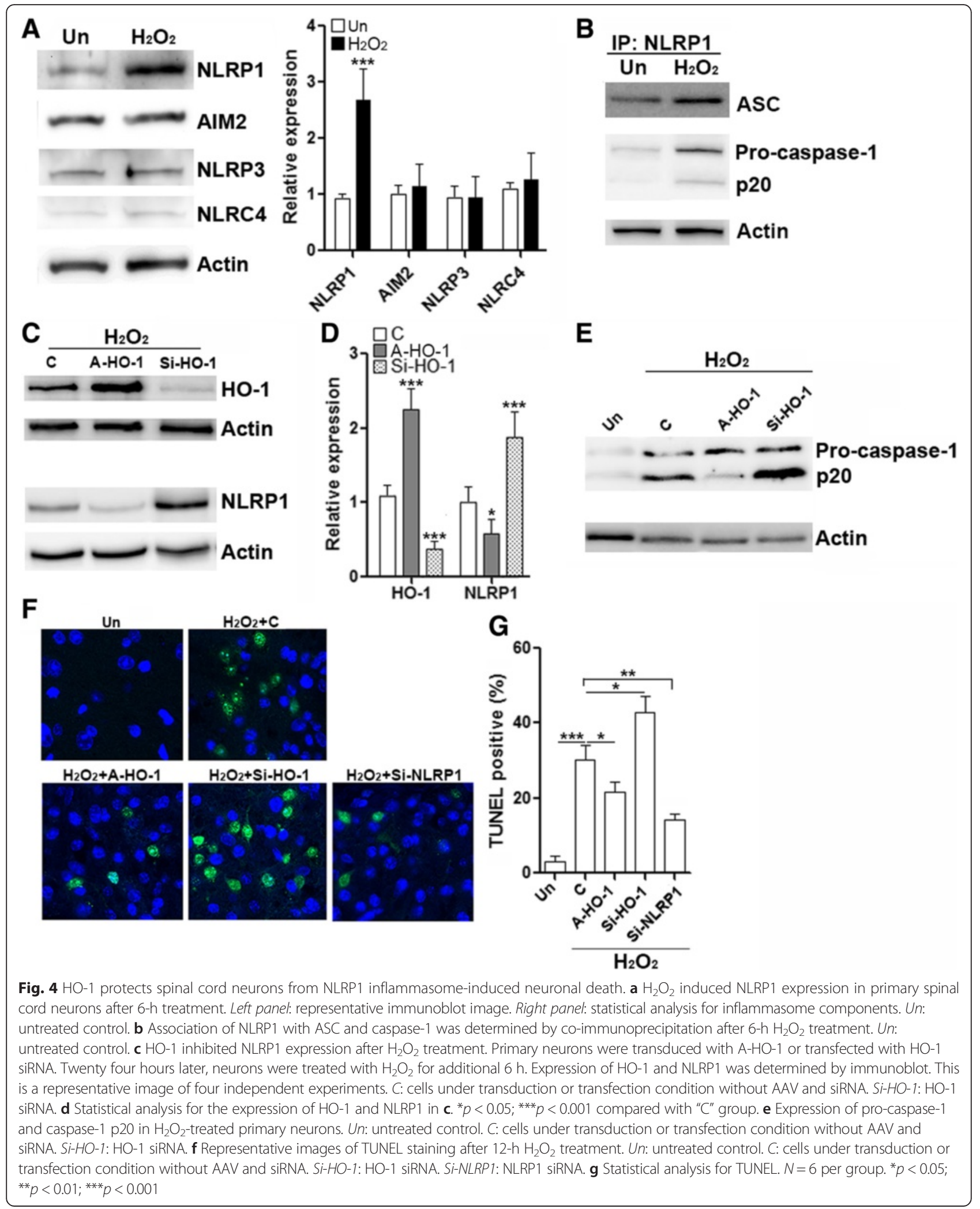



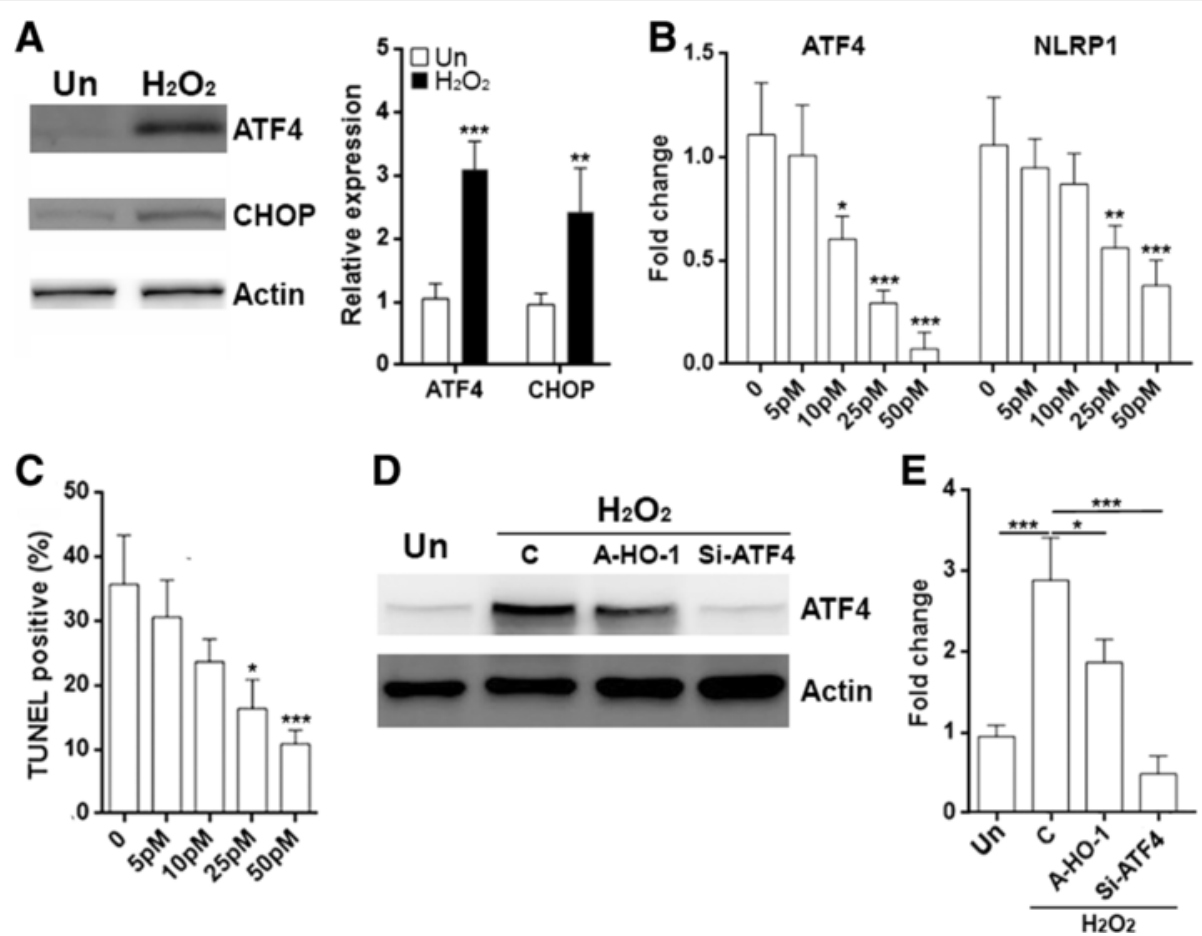

Fig. 5 HO-1 inhibits NLRP1 expression through ATF4. a Expression of ATF4 and CHOP in primary neurons were determined by immunoblot after 6-h $\mathrm{H}_{2} \mathrm{O}_{2}$ treatment. Left panel: representative immunoblot image. Right panel: statistical analysis for the expression of ATF4 and CHOP. Un: untreated control. $N=4$ per group. ${ }^{* *} p<0.001$ compared with "Un" group. $\mathbf{b}$ mRNA levels of ATF4 and NLRP1 in primary neurons. Primary neurons were transfected with different doses of ATF4 siRNA $48 \mathrm{~h}$ before treatment with $\mathrm{H}_{2} \mathrm{O}_{2}$ for additional $6 \mathrm{~h} . \mathrm{N}=3$ per group. ${ }^{*} p<0.05$; ${ }^{* *} p<0.01$; ${ }^{* * *} p<0.001$ compared with "O" group. $\mathbf{c}$ Neurons were treated as in $\mathbf{b}$, followed by detection of neuronal death with TUNEL after $12-\mathrm{h} \mathrm{H}_{2} \mathrm{O}_{2}$ treatment. $N=6$ per group. ${ }^{*} p<0.05 ;{ }^{* * *} p<0.001$ compared with " 0 " group. $\mathbf{d}$ Protein level of ATF4 in primary neurons. Primary neurons were transduced with A-HO-1 or transfected with ATF4 siRNA for $24 \mathrm{~h}$ before treatment with $\mathrm{H}_{2} \mathrm{O}_{2}$ for additional $6 \mathrm{~h}$. Un: untreated control. C: cells under transduction or transfection condition without AAV and siRNA. Si-ATF4: siRNA for ATF4. This is a representative of three independent experiments. e Neurons were treated as in $\mathbf{d}$. mRNA level of ATF4 was determined by q-RTPCR. $N=5$ per group. ${ }^{* *} p<0.01 ;{ }^{* * *} p<0.001$

expression after SCI (Additional file 1: Figure S4C). AHO-1 significantly increased HO-1 level in the post-SCI spinal cord in comparison with A-C (Fig. 6b). In addition, A-HO-1 significantly reduced ATF4 and NLRP1 expression after SCI compared with A-C but did not change the expression of NLRP3 and NLRC4 (Fig. 6b). Consistent with lower NLRP1 level, the expression of caspase-1 p20 was down-regulated by A-HO-1 (Fig. 6c). Interestingly, the expression of pro-caspase-1 was also reduced by A-HO-1 (Fig. 6c), suggesting that HO-1 might directly or indirectly inhibited caspase-1 expression in vivo. TUNEL revealed that A-HO-1 effectively decreased neuronal death after SCI (Fig. 6d). To assess the change of hindlimb locomotor function after SCI, the BBB score at pre-injury and $1,3,7,14$, and 21 days after SCI are shown in Fig. 6e. All rats initially showed a slight decrease in the BBB score, and there was no significant difference among the four groups before SCI. The sham group showed full recovery 3 days after SCI. The vehicle, A-C and A-HO-1 groups showed a sharp decrease in the BBB score 1 day after SCI. Partial improvements were observed, and there was no significant difference among the vehicle and A-C group after SCI. However, the neurological improvements were significantly greater in the A-HO-1 group compared to the improvements in the vehicle and A-C groups at 3,7 , 14, and 21 days after SCI.

\section{Discussion}

In this study, we examined the role of $\mathrm{HO}-1$ in regulating NLRP1 inflammasome formation and neuronal death after SCI. SCI consists of a primary mechanical injury and a secondary inflammatory injury and apoptosis [1]. The primary injury is locally restricted to the area of the vertebral fracture and is characterized by acute hemorrhage and ischemia. The secondary injury is characterized by further destruction of neurons and glial cells and leads to significant expansion of the damage, so that paralysis can extend to higher segments. After $\mathrm{SCI}$, cell death at the lesion site comprises both posttraumatic necrosis and apoptosis [41]. A time course analysis reveals that apoptosis occurs as early as $4 \mathrm{~h}$ post injury and can be seen in decreasing amounts as late as 3 weeks after SCI [42]. Apoptosis was observed in both 


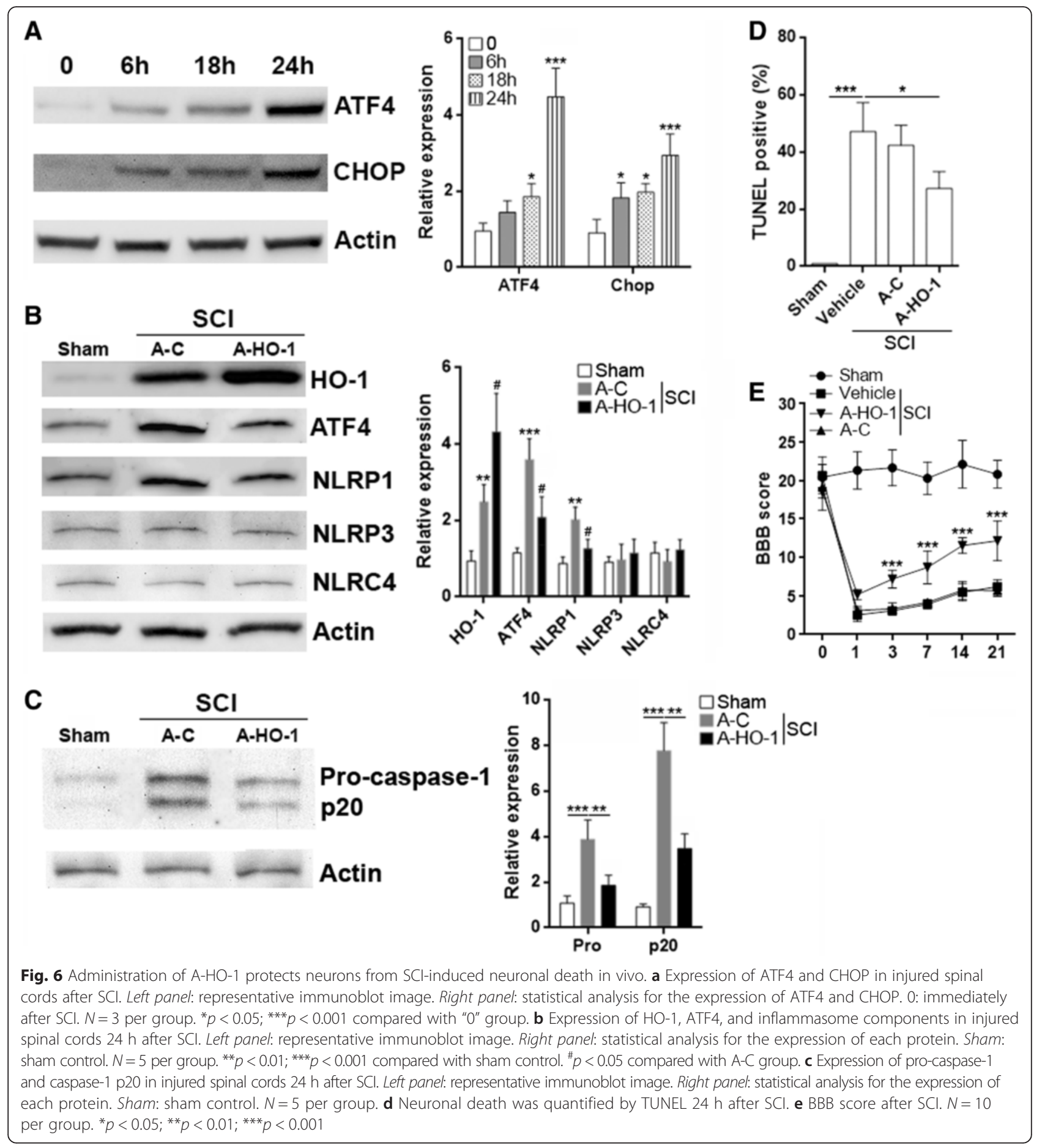

neurons and oligodendrocytes. Activation of caspase-3 or 9 occurs in neurons at the injury site within hours and in neurons distant from the injury site over a period of days. Although activation of caspase- 3 or 9 contributes to neuronal death, neuronal death can also be induced by caspase- 1 , which is activated directly via a CARD-containing inflammasome. Therefore, successful assembly and activation of inflammasomes are critical for the initiation of neuronal death. Although inflammasomes are generally formed in inflammatory immune cells, accumulating evidences have indicated that distinct types of inflammasomes are also present in neurons. NLRP1 inflammasomes mediate neuron injury under high glucose [43]. High extracellular potassium opens pannexin channels leading to inflammasome activation in primary neurons and astrocytes [44]. Importantly, recent studies 
have showed inflammasome formation in different neuronal disorders including SCI [12, 21, 38, 45].

Our study confirmed NLRP1 inflammasome formation in the spinal cord neurons after SCI. Interestingly, among the three NOD-like receptor proteins examined, only NLRP1 level was elevated after SCI. However, another study reported NLRP3 inflammasome formation in a SCI model [46]. The main difference between our model and their's is the spinal segmental levels receiving SCI: ours was spinal T12 and theirs was spinal T9. This disparity raised an interesting question of whether SCI performed on different spinal levels leads to activation of different inflammasome types. However, to our knowledge, no previous or current studies indicated different responses to insults/stimuli in different spinal segmental neurons. Hence, further investigation will be needed to elucidate the mechanism underlying this disparity.

In addition to elevated expression of NLRP1, ASC, and caspase-1, the association of these proteins was also up-regulated to form NLRP1 inflammasomes in injured spinal cord. The molecular signaling which triggers inflammasome assembly after SCI has been previously studied. It has been proposed that danger signals such as high plasma glucose, $\beta$-amyloid, Tolllike receptor (TLR) ligands, uric acid, and ATP induce inflammasome activation [47-51]. In particular, the engagement of ATP with P2X4 or P2X7 purinergic receptors induces inflammasome activation. Spinal cord neurons express $\mathrm{P} 2 \mathrm{X} 7$ purinergic receptors, and exposure to ATP led to high-frequency spiking, irreversible increases in cytosolic calcium, and cell death [52]. Systemic administration of an antagonist of P2X7 receptors improves recovery after SCI [53]. P2X4 receptors are expressed in spinal cord neurons and are responsible for inflammasome activation after SCI [45]. Importantly, SCI induces increase of ATP release in peritraumatic areas [52]. Therefore, it is highly possible that excessive ATP release activates these purinergic receptors to induce NLRP1 inflammasome formation. Another possibility is that TLRs might induce post-SCI NLRP1 inflammasome formation. Although TLRs are generally considered to be expressed in microglia and astrocytes, recent research has showed that TLR expression in neurons is pivotal under both physiological and pathological conditions [54-57]. Perhaps SCI changes expression of certain TLRs which recognize danger signals after injury and subsequently causes inflammasome formation. Further study will be performed to test this hypothesis.

The induction of HO-1 after SCI is consistent with a previous report [31]. However, the exact mechanisms underlying this induction have not been completely understood. Hemin could be one of the candidates which induce HO-1 expression, since a study stated that hemin induces HO-1 in spinal cord vasculature after SCI [58]. It is possible that hemin is released from red blood cells into the interstitial space as a result of hemorrhage after SCI. Cultured cerebellar granular neurons express heme carrier protein 1 (HCP1), and HCP1 contributes to the time- and concentration-dependent accumulation of hemin in neurons, which causes substantial neurotoxicity [59]. However, to our knowledge, there is no information about HCP1 expression in spinal cord neurons. Thus, further study will be needed to investigate the effect of hemin on spinal cord neurons. Other factors, such as hypoxia, reactive oxygen species, and pro-inflammatory cytokines can also regulate $\mathrm{HO}-1$ expression in different cell types [60]. Perhaps the postSCI HO-1 expression is a combined effect of above factors rather than the effect of a single factor. Of note, the HO- 1 induction peaked at $18 \mathrm{~h}$ after SCI and was decreased at $24 \mathrm{~h}$ with respect to $18 \mathrm{~h}$. This dynamic change of HO-1 expression might be explained by the transcriptional repression through Bach1. Bach1 is a transcriptional repressor of heme oxygenase-1 gene. A similar decrease of HO-1 expression by Bach1 is observed in rat fibroblasts and human lung cancer cells exposed to cigarette smoke condensate in a previous study [61]. In addition, genetic ablation of Bach1 leads to upregulation of $\mathrm{HO}-1$ in myocardial ischemia/reperfusion and SCI in mice [62, 63]. Moreover, HO-1 induction is also associated with down-regulation of Bach1 in ischemic brains [64]. However, the kinetics of Bach1 expression after compressive SCI is not fully understood. Interestingly, hypoxia-inducible factor-1 (HIF-1), which is up-regulated in injured spinal cords [65], induces the expression of Bach1 [66, 67]. Therefore, it is possible that down-regulation of $\mathrm{HO}-1$ at $24 \mathrm{~h}$ is due to upregulation of Bach1 by HIF-1. Future investigation will be needed to verify this hypothesis.

The anti-inflammatory role of HO-1 has been reported previously. Hemin-induced HO-1 inhibits NLRP3 inflammasome formation in acute lung injury [68]. Induction of HO-1 attenuates lipopolysaccharide-induced inflammasome formation in human gingival epithelial cells [69]. However, up-regulation of HO-1 is not always anti-inflammatory. The $\mathrm{HO}$ activity may exert a different effect on inflammation. Navarra et al. reported that HO activation blunts the systemic response to stressors [70]. In addition, Barone et al. found that HO-1 demonstrates increased serine residue phosphorylation and oxidative post-translational modifications in hippocampus and cerebellum in Alzheimer's disease, suggesting HO-1 as a target of oxidative damage even in the cerebellum [71]. This serine residue phosphorylation may influence the HO-1 activity [72]. Therefore, elucidation of the exact role of $\mathrm{HO}$ in the neuropathy including SCI needs more elaborated research designs. In our study, HO-1 inhibits 
post-SCI NLRP1 expression via the transcription factor ATF4, indicating HO-1 is likely anti-inflammatory in the local SCI area. To our knowledge, we are the first to report the role of HO-1 in regulating ATF4 expression. Previous studies imply that ATF4 positively regulates HO-1 expression [73, 74], but no evidence has shown the effect of HO-1 on ATF4 expression. The mechanism by which HO-1 down-regulates ATF4 is still unknown. Based on the fact that cytosolic HO-1 is able to translocate into the nuclei of certain tumor cells [75-77], it is possible that HO-1 could directly act as a transcription suppressor or indirectly regulate some transcription factors to inhibit ATF4 expression. It has been reported that HO-1 modulates subcellular distribution and activation of Nrf2 [75], suggesting HO-1 is able to influence the activity of certain transcription factors. However, in our study, HO-1 seems to be located only in the cytosol, excluding its effect in the nucleus. We speculated that HO-1 might regulate ATF4 expression through other mechanisms rather than acting as a transcription suppressor. Our ongoing study is analyzing the downstream molecules of HO-1 signaling in an effort to assess which factor is responsible for this effect.

Inflammasome-associated neuronal death has been a research interest both in basic and clinical studies. With inflammasomes, pro-caspase- 1 is activated. Its function includes conversion of the pro-IL-1 $\beta$ and pro-IL-18 into active IL-1 $\beta$ and IL-18. Cell membrane integrity is destroyed as a result of micropore formation caused by caspase-1, IL-1 $\beta$, and IL-18. These micropores lead to a series of processes such as cytoplasm release, cell osmotic lysis, and inflammatory reaction. In addition, Caspase- 1 is involved in degradation of DNA and chromosomes because a specific endonuclease is activated by caspase-1. Caspase-1 also triggers degradation of cytoskeletal proteins. In our study, NLRP1 inflammasomes were closely related to post-SCI neuronal death. However, it is still unclear which cell death type apoptosis, pyroptosis, or necrosis is dominant in the acute phase of SCI. It is plausible that each death type contributes to neuronal death at a certain time period during and after $\mathrm{SCI}$, depending on the duration and severity of SCI. At the beginning of $\mathrm{SCI}$, the injury stress might directly cause apoptosis or necrosis when inflammasomes have not been activated. Later on, when less damaged neurons and neurons in the penumbra are under inflammatory stress, the pyroptosis could couple with apoptosis to enhance the secondary injury. A recent study showed that AIM2 and NLRP3 inflammasomes activate both apoptotic and pyroptotic death pathways [78], making the relationship between apoptosis and pyroptosis more complicated. An elaborated study on the post-SCI cell death types will be needed to elucidate the neuronal death processes during and after SCI.
Consistent with the anti-inflammatory effect of HO-1 in most cases $[22,79,80]$, our study found that HO-1 inhibits inflammasome-induced neuronal death. Whether HO-1 has the similar or different efficacy in other neuronal disorders such as ischemic stroke, Alzheimer's disease, and multiple sclerosis needs further investigation. Our study demonstrates a new mechanism by which HO-1 protects neurons from SCI and might provide new therapeutic clues for treating SCI.

\section{Conclusions}

NLRP1 inflammasomes were assembled and activated in neurons after spinal cord injury (SCI). HO-1 expression was induced in spinal cord neurons in association with the formation of NLRP1 inflammasomes. Administration of HO-1-expressing adeno-associated virus into spinal cords before SCI effectively decreased SCI-induced NLRP1 inflammasome formation, alleviated neuronal death, and improved functional recovery. HO-1 downregulates NLRP1 expression through inhibiting expression of ATF4. Our study demonstrates a new mechanism by which $\mathrm{HO}-1$ protects neurons from SCI.

\section{Additional file}

Additional file 1: Figures S1-S4. Figure S1. Manipulation of expression
of $\mathrm{HO}-1$ and NLRP1. Figure S2. TUNEL after transfection with scramble
siRNA or control AAV. Figure S3. ATF4 expression after transduction with
control AAV. Figure S4. Administration of AAV in vivo. (DOCX $2178 \mathrm{~kb}$ )

\section{Abbreviations}

AAV: adeno-associated virus; ASC: apoptosis-associated speck-like protein containing a caspase recruitment domain; ATF4: activating transcription factor 4; CNS: central nervous system; DMEM: Dulbecco's Modified Eagle Medium; ER: endoplasmic reticulum; FBS: fetal bovine serum; HBSS: Hank's balanced salt solution; HCP1: heme carrier protein 1; HO: heme oxygenase; IL-1 $\beta$ : interleukin-1 $\beta$; NLRP1: tyrosine hydroxylase; nucleotide-binding-andoligomerization domain-like receptor protein-1; SCl: spinal cord injury; TNF-a: tumor necrosis factor-a; TUNEL: terminal deoxynucleotidyl transferase dUTP nick end labeling.

\section{Competing interests}

The authors declare that they have no competing interests.

\section{Author's contributions}

WPL, GPX, QL, QFK, and JHL were involved in the design of the study, carried out the experiments, and participated in the data analysis and manuscript preparation. XWC, LQZ, and JXS contributed to the data analysis and interpretation of the results. All authors read and approved the final manuscript.

\section{Acknowledgements}

This study was supported by a grant from the National Natural Science Foundation of China (NO. 81201403), the Scientific Research Project of Quanzhou City Administration of Science \& Technology (NO. 2012Z31), and the Special Fund for Training Outstanding Talents of Quanzhou City.

\section{Author details}

'Department of Orthopedic Surgery, the Second Affiliated Hospital, Fujian Medical University, Quanzhou 362000, China. ${ }^{2}$ Hepatology Unit, Xiamen Hospital of Traditional Chinese Medicine, Xiamen 361009, China.

${ }^{3}$ Department of Human Anatomy, Histology and Embryology, School of Basic 
Medical Sciences, Fujian Medical University, Fuzhou 350108, China. ${ }^{4}$ Department of Orthopedic Surgery, the First Affiliated Hospital, Fujian Medical University, Fuzhou 350004, China.

\section{Received: 26 December 2015 Accepted: 22 February 2016} Published online: 29 February 2016

\section{References}

1. Zhang N, Yin Y, Xu SJ, Wu YP, Chen WS. Inflammation \& apoptosis in spinal cord injury. Indian J Med Res. 2012;135:287-96.

2. Liu NK, Zhang YP, Titsworth WL, Jiang X, Han S, Lu PH, et al. A novel role of phospholipase A2 in mediating spinal cord secondary injury. Ann Neurol. 2006:59:606-19.

3. Ren Y, Young W. Managing inflammation after spinal cord injury through manipulation of macrophage function. Neural Plast. 2013:2013:945034.

4. Liu XZ, Xu XM, Hu R, Du C, Zhang SX, McDonald JW, et al. Neuronal and glial apoptosis after traumatic spinal cord injury. J Neurosci. 1997;17:5395-406.

5. Di Giovanni S, Knoblach SM, Brandoli C, Aden SA, Hoffman EP, Faden Al. Gene profiling in spinal cord injury shows role of cell cycle in neuronal death. Ann Neurol. 2003:53:454-68.

6. Beattie MS, Hermann GE, Rogers RC, Bresnahan JC. Cell death in models of spinal cord injury. Prog Brain Res. 2002;137:37-47.

7. Liu S, Sarkar C, Dinizo M, Faden Al, Koh EY, Lipinski MM, et al. Disrupted autophagy after spinal cord injury is associated with ER stress and neuronal cell death. Cell Death Dis. 2015;6, e1582.

8. Park E, Velumian AA, Fehlings MG. The role of excitotoxicity in secondary mechanisms of spinal cord injury: a review with an emphasis on the implications for white matter degeneration. J Neurotrauma. 2004;21:754-74.

9. Kaushal V, Dye R, Pakavathkumar P, Foveau B, Flores J, Hyman B, et al. Neuronal NLRP1 inflammasome activation of Caspase-1 coordinately regulates inflammatory interleukin-1-beta production and axonal degeneration-associated Caspase-6 activation. Cell Death Differ. 2015;22:1676-86

10. Adamczak SE, de Rivero Vaccari JP, Dale G, Brand 3rd FJ, Nonner D, Bullock $M R$, et al. Pyroptotic neuronal cell death mediated by the AIM2 inflammasome. J Cereb Blood Flow Metab. 2014;34:621-9.

11. Fann DY, Lee SY, Manzanero S, Tang SC, Gelderblom M, Chunduri P, et al. Intravenous immunoglobulin suppresses NLRP1 and NLRP3 inflammasomemediated neuronal death in ischemic stroke. Cell Death Dis. 2013:4, e790.

12. Tan CC, Zhang JG, Tan MS, Chen H, Meng DW, Jiang T, et al. NLRP1 inflammasome is activated in patients with medial temporal lobe epilepsy and contributes to neuronal pyroptosis in amygdala kindling-induced rat model. J Neuroinflammation. 2015;12:18.

13. Jorgensen I, Miao EA. Pyroptotic cell death defends against intracellular pathogens. Immunol Rev. 2015;265:130-42.

14. Martinon F, Burns K, Tschopp J. The inflammasome: a molecular platform triggering activation of inflammatory caspases and processing of prolL-beta. Mol Cell. 2002;10:417-26.

15. Bergsbaken T, Fink SL, Cookson BT. Pyroptosis: host cell death and inflammation. Nat Rev Microbiol. 2009:7:99-109.

16. Latz E, Xiao TS, Stutz A. Activation and regulation of the inflammasomes. Nat Rev Immunol. 2013;13:397-411.

17. Tringali G, Mancuso C, Mirtella A, Pozzoli G, Parente L, Preziosi P, et al. Evidence for the neuronal origin of immunoreactive interleukin-1 beta released by rat hypothalamic explants. Neurosci Lett. 1996;219:143-6.

18. Tringali G, Mirtella A, Mancuso C, Guerriero G, Preziosi P, Navarra P. The release of immunoreactive interleukin-1 beta from rat hypothalamic explants is modulated by neurotransmitters and corticotropin-releasing hormone. Pharmacol Res. 1997:36:269-73.

19. Abulafia DP, de Rivero Vaccari JP, Lozano JD, Lotocki G, Keane RW, Dietrich WD. Inhibition of the inflammasome complex reduces the inflammatory response after thromboembolic stroke in mice. J Cereb Blood Flow Metab. 2009:29:534-44.

20. de Rivero Vaccari JP, Lotocki G, Alonso OF, Bramlett HM, Dietrich WD, Keane RW. Therapeutic neutralization of the NLRP1 inflammasome reduces the innate immune response and improves histopathology after traumatic brain injury. J Cereb Blood Flow Metab. 2009;29:1251-61.

21. de Rivero Vaccari JP, Brand F, 3rd, Adamczak S, Lee SW, Barcena JP, Wang MY, Bullock MR, Dietrich WD, Keane RW. Exosome-mediated inflammasome signaling after central nervous system injury. J Neurochem. 2015;21(Suppl 1):39-48.
22. Paine A, Eiz-Vesper B, Blasczyk R, Immenschuh S. Signaling to heme oxygenase-1 and its anti-inflammatory therapeutic potential. Biochem Pharmacol. 2010;80:1895-903.

23. Mancuso C, Barone E. The heme oxygenase/biliverdin reductase pathway in drug research and development. Curr Drug Metab. 2009;10:579-94.

24. Raju VS, McCoubrey Jr WK, Maines MD. Regulation of heme oxygenase-2 by glucocorticoids in neonatal rat brain: characterization of a functional glucocorticoid response element. Biochim Biophys Acta. 1997;1351:89-104.

25. Maines MD. The heme oxygenase system: a regulator of second messenger gases. Annu Rev Pharmacol Toxicol. 1997;37:517-54

26. Okinaga S, Takahashi K, Takeda K, Yoshizawa M, Fujita H, Sasaki H, et al. Regulation of human heme oxygenase-1 gene expression under thermal stress. Blood. 1996:87:5074-84.

27. Cantoni L, Rossi C, Rizzardini M, Gadina M, Ghezzi P. Interleukin-1 and tumour necrosis factor induce hepatic haem oxygenase. Feedback regulation by glucocorticoids. Biochem J. 1991;279(Pt 3):891-4.

28. Gozzelino R, Jeney V, Soares MP. Mechanisms of cell protection by heme oxygenase-1. Annu Rev Pharmacol Toxicol. 2010;50:323-54.

29. Mancuso C, Preziosi P, Grossman AB, Navarra P. The role of carbon monoxide in the regulation of neuroendocrine function. Neuroimmunomodulation. 1997:4:225-9.

30. Mancuso C, Ragazzoni E, Tringali G, Liberale I, Preziosi P, Grossman A, et al. Inhibition of heme oxygenase in the central nervous system potentiates endotoxin-induced vasopressin release in the rat. J Neuroimmunol. 1999;99:189-94

31. Panahian N, Maines MD. Site of injury-directed induction of heme oxygenase-1 and -2 in experimental spinal cord injury: differential functions in neuronal defense mechanisms? J Neurochem. 2001:76:539-54.

32. Yamada K, Tanaka N, Nakanishi K, Kamei N, Ishikawa M, Mizuno T, et al. Modulation of the secondary injury process after spinal cord injury in Bach1deficient mice by heme oxygenase-1. J Neurosurg Spine. 2008;9:611-20.

33. Lin Y, Vreman HJ, Wong RJ, Tjoa T, Yamauchi T, Noble-Haeusslein LJ. Heme oxygenase-1 stabilizes the blood-spinal cord barrier and limits oxidative stress and white matter damage in the acutely injured murine spinal cord. J Cereb Blood Flow Metab. 2007;27:1010-21.

34. Hall JC, Priestley JV, Perry VH, Michael-Titus AT. Docosahexaenoic acid, but not eicosapentaenoic acid, reduces the early inflammatory response following compression spinal cord injury in the rat. J Neurochem. 2012;121:738-50.

35. Kehl LJ, Fairbanks CA, Laughlin TM, Wilcox GL. Neurogenesis in postnatal rat spinal cord: a study in primary culture. Science. 1997;276:586-9.

36. Anderson KN, Potter AC, Piccenna LG, Quah AK, Davies KE, Cheema SS. Isolation and culture of motor neurons from the newborn mouse spinal cord. Brain Res Brain Res Protoc. 2004:12:132-6.

37. Basso DM, Beattie MS, Bresnahan JC. A sensitive and reliable locomotor rating scale for open field testing in rats. J Neurotrauma. 1995;12:1-21.

38. Walsh JG, Muruve DA, Power C. Inflammasomes in the CNS. Nat Rev Neurosci. 2014:15:84-97.

39. D'Osualdo A, Anania VG, Yu K, Lill JR, Kaufman RJ, Matsuzawa S, et al. Transcription factor ATF4 induces NLRP1 inflammasome expression during endoplasmic reticulum stress. PLoS One. 2015;10, e0130635

40. Matsuyama D, Watanabe M, Suyama K, Kuroiwa M, Mochida J. Endoplasmic reticulum stress response in the rat contusive spinal cord injury modelsusceptibility in specific cell types. Spinal Cord. 2014:52:9-16.

41. Byrnes KR, Stoica BA, Fricke S, Di Giovanni S, Faden Al. Cell cycle activation contributes to post-mitotic cell death and secondary damage after spinal cord injury. Brain. 2007;130:2977-92.

42. Mizuno Y, Mochizuki H, Sugita Y, Goto K. Apoptosis in neurodegenerative disorders. Intern Med. 1998;37:192-3.

43. Meng XF, Wang XL, Tian XJ, Yang ZH, Chu GP, Zhang J, et al. Nod-like receptor protein 1 inflammasome mediates neuron injury under high glucose. Mol Neurobiol. 2014;49:673-84.

44. Silverman WR, de Rivero Vaccari JP, Locovei S, Qiu F, Carlsson SK, Scemes E, et al. The pannexin 1 channel activates the inflammasome in neurons and astrocytes. J Biol Chem. 2009:284:18143-51.

45. de Rivero Vaccari JP, Bastien D, Yurcisin G, Pineau I, Dietrich WD, De Koninck $Y$, et al. P2X4 receptors influence inflammasome activation after spinal cord injury. J Neurosci. 2012;32:3058-66.

46. Zendedel A, Johann S, Mehrabi S, Joghataei MT, Hassanzadeh G, Kipp M, Beyer C. Activation and regulation of NLRP3 inflammasome by intrathecal application of SDF-1a in a spinal cord injury model. Mol Neurobiol. 2015. Epub ahead of print. 
47. Alnemri ES. Sensing cytoplasmic danger signals by the inflammasome. J Clin Immunol. 2010;30:512-9.

48. Pedra JH, Cassel SL, Sutterwala FS. Sensing pathogens and danger signals by the inflammasome. Curr Opin Immunol. 2009:21:10-6.

49. Hanamsagar R, Hanke ML, Kielian T. Toll-like receptor (TLR) and inflammasome actions in the central nervous system. Trends Immunol. 2012;33:333-42.

50. Gold M, El Khoury J. Beta-amyloid, microglia, and the inflammasome in Alzheimer's disease. Semin Immunopathol. 2015;37:607-11.

51. Schnaars M, Beckert $H$, Halle A. Assessing beta-amyloid-induced NLRP3 inflammasome activation in primary microglia. Methods Mol Biol. 2013;1040:1-8.

52. Wang $X$, Arcuino G, Takano T, Lin J, Peng WG, Wan P, et al. P2X7 receptor inhibition improves recovery after spinal cord injury. Nat Med. 2004;10:821-7.

53. Peng W, Cotrina ML, Han X, Yu H, Bekar L, Blum L, et al. Systemic administration of an antagonist of the ATP-sensitive receptor P2X7 improves recovery after spinal cord injury. Proc Natl Acad Sci U S A. 2009;106:12489-93.

54. Lafon M, Megret F, Lafage M, Prehaud C. The innate immune facet of brain: human neurons express TLR-3 and sense viral dsRNA. J Mol Neurosci. 2006;29:185-94.

55. Tang SC, Arumugam TV, Xu X, Cheng A, Mughal MR, Jo DG, et al. Pivotal role for neuronal Toll-like receptors in ischemic brain injury and functional deficits. Proc Natl Acad Sci U S A. 2007;104:13798-803.

56. Peltier DC, Simms A, Farmer JR, Miller DJ. Human neuronal cells possess functional cytoplasmic and TLR-mediated innate immune pathways influenced by phosphatidylinositol-3 kinase signaling. J Immunol. 2010;184:7010-21.

57. Leow-Dyke S, Allen C, Denes A, Nilsson O, Maysami S, Bowie AG, et al. Neuronal Toll-like receptor 4 signaling induces brain endothelial activation and neutrophil transmigration in vitro. J Neuroinflammation. 2012;9:230.

58. Yamauchi T, Lin Y, Sharp FR, Noble-Haeusslein LJ. Hemin induces heme oxygenase-1 in spinal cord vasculature and attenuates barrier disruption and neutrophil infiltration in the injured murine spinal cord. J Neurotrauma. 2004:21:1017-30

59. Dang TN, Robinson SR, Dringen R, Bishop GM. Uptake, metabolism and toxicity of hemin in cultured neurons. Neurochem Int. 2011;58:804-11.

60. Choi AM, Alam J. Heme oxygenase-1: function, regulation, and implication of a novel stress-inducible protein in oxidant-induced lung injury. Am J Respir Cell Mol Biol. 1996;15:9-19.

61. Palozza P, Serini S, Curro D, Calviello G, Igarashi K, Mancuso C. betaCarotene and cigarette smoke condensate regulate heme oxygenase-1 and its repressor factor Bach1: relationship with cell growth. Antioxid Redox Signal. 2006;8:1069-80.

62. Yano Y, Ozono R, Oishi Y, Kambe M, Yoshizumi M, Ishida T, et al. Genetic ablation of the transcription repressor Bach1 leads to myocardial protection against ischemia/reperfusion in mice. Genes Cells. 2006;11:791-803.

63. Kanno H, Ozawa H, Dohi Y, Sekiguchi A, Igarashi K, Itoi E. Genetic ablation of transcription repressor Bach1 reduces neural tissue damage and improves locomotor function after spinal cord injury in mice. J Neurotrauma. 2009;26:31-9.

64. Perez-de-Puig I, Martin A, Gorina R, de la Rosa X, Martinez E, Planas AM. Induction of hemeoxygenase-1 expression after inhibition of hemeoxygenase activity promotes inflammation and worsens ischemic brain damage in mice. Neuroscience. 2013;243:22-32.

65. Xiaowei H, Ninghui Z, Wei X, Yiping T, Linfeng X. The experimental study of hypoxia-inducible factor-1alpha and its target genes in spinal cord injury. Spinal Cord. 2006;44:35-43.

66. Florczyk U, Czauderna S, Stachurska A, Tertil M, Nowak W, Kozakowska M, et al. Opposite effects of HIF-1alpha and HIF-2alpha on the regulation of IL-8 expression in endothelial cells. Free Radic Biol Med. 2011;51:1882-92.

67. Loboda A, Stachurska A, Florczyk U, Rudnicka D, Jazwa A, Wegrzyn J, et al. HIF-1 induction attenuates Nrf2-dependent IL-8 expression in human endothelial cells. Antioxid Redox Signal. 2009;11:1501-17.

68. Luo YP, Jiang L, Kang K, Fei DS, Meng XL, Nan CC, et al. Hemin inhibits NLRP3 inflammasome activation in sepsis-induced acute lung injury, involving heme oxygenase-1. Int Immunopharmacol. 2014;20:24-32.

69. Li H, Zhou X, Zhang J. Induction of heme oxygenase-1 attenuates lipopolysaccharide-induced inflammasome activation in human gingival epithelial cells. Int J Mol Med. 2014;34:1039-44.
70. Navarra P, Dello Russo C, Mancuso C, Preziosi P, Grossman A. Gaseous neuromodulators in the control of neuroendocrine stress axis. Ann N Y Acad Sci. 2000;917:638-46.

71. Barone E, Di Domenico F, Sultana R, Coccia R, Mancuso C, Perluigi M, et al. Heme oxygenase-1 posttranslational modifications in the brain of subjects with Alzheimer disease and mild cognitive impairment. Free Radic Biol Med. 2012;52:2292-301.

72. Salinas M, Wang J, Rosa de Sagarra M, Martin D, Rojo Al, Martin-Perez J, et al. Protein kinase Akt/PKB phosphorylates heme oxygenase-1 in vitro and in vivo. FEBS Lett. 2004;578:90-4.

73. He CH, Gong P, Hu B, Stewart D, Choi ME, Choi AM, et al. Identification of activating transcription factor 4 (ATF4) as an Nrf2-interacting protein. Implication for heme oxygenase-1 gene regulation. J Biol Chem. 2001;276:20858-65.

74. Dey S, Sayers CM, Verginadis II, Lehman SL, Cheng Y, Cerniglia GJ, et al. ATF4-dependent induction of heme oxygenase 1 prevents anoikis and promotes metastasis. J Clin Invest. 2015;125:2592-608.

75. Biswas C, Shah N, Muthu M, La P, Fernando AP, Sengupta S, et al. Nuclear heme oxygenase-1 (HO-1) modulates subcellular distribution and activation of Nrf2, impacting metabolic and anti-oxidant defenses. J Biol Chem. 2014;289:26882-94.

76. Gandini NA, Fermento ME, Salomon DG, Blasco J, Patel V, Gutkind JS, et al. Nuclear localization of heme oxygenase-1 is associated with tumor progression of head and neck squamous cell carcinomas. Exp Mol Pathol. 2012;93:237-45.

77. Tibullo D, Barbagallo I, Giallongo C, La Cava P, Parrinello N, Vanella L, et al. Nuclear translocation of heme oxygenase-1 confers resistance to imatinib in chronic myeloid leukemia cells. Curr Pharm Des. 2013;19:2765-70.

78. Sagulenko V, Thygesen SJ, Sester DP, Idris A, Cridland JA, Vajjhala PR, et al. AIM2 and NLRP3 inflammasomes activate both apoptotic and pyroptotic death pathways via ASC. Cell Death Differ. 2013;20:1149-60.

79. Chen HG, Xie KL, Han HZ, Wang WN, Liu DQ, Wang GL, et al. Heme oxygenase-1 mediates the anti-inflammatory effect of molecular hydrogen in LPS-stimulated RAW 264.7 macrophages. Int J Surg. 2013;11:1060-6.

80. Lee TS, Chau LY. Heme oxygenase-1 mediates the anti-inflammatory effect of interleukin-10 in mice. Nat Med. 2002;8:240-6.

\section{Submit your next manuscript to BioMed Central and we will help you at every step:}

- We accept pre-submission inquiries

- Our selector tool helps you to find the most relevant journal

- We provide round the clock customer support

- Convenient online submission

- Thorough peer review

- Inclusion in PubMed and all major indexing services

- Maximum visibility for your research

Submit your manuscript at www.biomedcentral.com/submit
Biomed Central 